\title{
TEKNIK PEMBIBITAN DAN PENANAMAN MANGROVE DI BANYUURIP MANGROVE CENTER, DESA BANYUURIP, KECAMATAN UJUNGPANGKAH, KABUPATEN GRESIK
}

\author{
Defri Yona $^{\# 1}$, Nurin Hidayati*2, Syarifah Hikmah Julinda Sari ${ }^{\# 3}$, Irfan Naufal Amar ${ }^{\# 4}$, Kharisma \\ Wisnu Sesanty\#5 \\ 1Fakultas Perikanan dan Ilmu Kelautan, Universitas Brawijaya, Jalan Veteran Malang 65145 \\ ${ }^{2}$ Marine Research Exploration and Management (MEXMA) Research Group, Universitas Brawijaya, \\ Malang 65145 \\ *Corresponding author email: defri.yona@ub.ac.id
}

\begin{abstract}
ABSTRAK
Banyuurip is one village in East Java that has successfully replanting its mangrove forest. Mangrove forest in Banyuurip had experienced losses due to changes into aquaculture and also abrasion from the Java Sea. However, with the concern and willingness of local fishermen who realized the loss of mangrove brought significant impact to their fish catching, mangrove replanting was carried out since 2007. This effort went well because they did the seedling process by themselves. Seedling process in Banyuurip is dominated by mangrove Avicennia sp and Rhizophora because these mangroves are found in high numbers in Banyuurip. Seedling is carried out using polybag and the germination was conducted in an area called 'bedengan' to protect the seeds from the sun. The seeds are watered using water pump regularly and supervision is conducted to prevent the seeds from being eaten by crab. At present, mangrove seedling in Banyuurip is running well and the seeds are either used by themselves or are selling to another mangrove places.
\end{abstract}

Keywords - mangrove, replanting, seedling and germination, Banyuurip, Gresik

\section{PENDAHULUAN}

Mangrove adalah sebuah ekosistem yang terdapat diantara lingkungan darat dan laut. Ekosistem mangrove ditemukan secara global mulai dari daerah tropis sampai subtropis dengan luasan mencapai $152.308 \mathrm{~km}^{2}$ (Spalding et al., 2010). Di Indonesia, luas mangrove pada tahun 1999 adalah 3,5 juta hektar (Noor et al., 2002) dan terus mengalami penurunan luas karena berbagai kerusakan baik secara alami maupun akibat aktifitas manusia (Gunarto, 2004; Suryawan, 2007). Beberapa faktor yang dapat menyebabkan kerusakan mangrove diantaranya adalah penebangan hutan mangrove untuk alih fungsi lahan seperti perubahan menjadi areal tambak (Pontoh, 2011), sedimentasi yang mengakibatkan terganggunya pertumbuhan mangrove maupun masuknya limbah baik limbah domestik maupun industri.

Sebagai sebuah ekosistem, mangrove merupakan habitat bagi berbagai biota. Nagelkerken et al. (2008) dalam reviewnya tentang fungsi mangrove sebagai habitat bagi biota darat dan laut membagi habitat hutan mangrove menjadi: habitat di atas mangrove yang dihuni oleh burung, serangga, mamalia dan reptil; habitat di bawah air dihuni oleh sponge, alga dan bivalvia; dan habitat di antara akarakar mangrove yang dihuni oleh ikan, kepiting maupun udang. Banyaknya jenis biota yang menghuni mangrove karena ekosistem ini menyediakan berbagai jenis sumber makanan mulai dari serasah-serasah mangrove hingga mangsa bagi jenis-jenis predator seperti buaya. Selain itu, mangrove juga menjadi nursery ground bagi biota-biota tersebut karena hutan mangrove menyediakan perlindungan dari predator (Gunarto, 2004; Nagelkerken et al., 2008). Oleh karena pentingnya hutan mangrove, kerusakan terhadap hutan mangrove dapat mengancam kehidupan organisme lain yang pada akhirnya juga dapat mengancam kehidupan manusia.

Rehabilitasi hutan mangrove dapat dilakukan dengan permudaan kawasan mangrove atau reboisasi mangrove. Permudaan mangrove dapat dilakukan dengan cara alami maupun buatan. Permudaan dengan cara alami terjadi jika buah jatuh dan tumbuh dengan sendirinya pada substrat. Permudaan buatan dilakukan oleh manusia dengan cara melakukan pembibitan dan penanaman kembali bibit-bibit yang telah tumbuh tersebut pada habitat alaminya. Proses permudaan alami berdasarkan 
Bengen (1999) dapat terjadi pada jenis mangrove tertentu seperti Bruguiera dan Rhizophora yang memiliki bentuk benih khusus. Benih ini dapat tumbuh berkecambah saat masih berada pada pohon induk. Pada proses ini, benih terus mengalami pertumbuhan tanpa istirahat dimana beratnya terus bertambah sehingga menjadi lebih berat dibandingkan bagian terluarnya dan mudah untuk terlepas. Benih yang sudah terlepas ini akan jatuh ke habitat alami, mengapung di air dan terbawa aliran air sampai memasuki perairan yang cukup dangkal dan ujung akarnya dapat mencapai dasar. Benih yang telah menancap pada substrat ini selanjutnya dapat tumbuh menjadi pohon. Permudaan dengan cara alami cenderung memiliki faktor keberhasilan yang rendah karena buah atau biji yang terlalu kecil dapat sangat mudah terbawa arus ataupun dimakan oleh predator.

Mangrove Center Banyuurip terletak di

Desa Banyuurip, Kecamatan Ujungpangkah, Kabupaten Gresik, Jawa Timur (Gambar 1) yang merupakan sebuah hutan mangrove yang dikembangkan menjadi daerah wisata berbasis lingkungan dan masyarakat. Hutan mangrove ini merupakan hutan rehabilitasi dimana penanaman kembali dilakukan oleh sekelompok nelayan yang merasa kehilangan mata pencaharian karena berkurangnya biota seperti kepiting dan kerang yang sebelumnya banyak ditemukan di hutan mangrove. Hal ini terjadi karena rusaknya hutan mangrove akibat dari abrasi pantai yang terjadi sejak tahun 2004. Selain itu, kerusakan mangrove juga diakibatkan oleh penebangan mangrove untuk perluasan lahan tambak dan juga kepentingan pribadi tanpa adanya usaha reboisasi. Beberapa nelayan yang peduli terhadap kelestarian mangrove selanjutnya membentuk Kelompok Pelestari Mangrove yang bergerak untuk menumbuhkan kesadaran peduli lingkungan kepada masyarakat dengan menjadikan wilayah pesisir Banyuurip sebagai kawasan mangrove yang asri berbasis nelayan, tempat migrasi burung dan tempat pembelajaran pembibitan mangrove dan tanaman pantai lainnya (Banyuurip Mangrove Center).

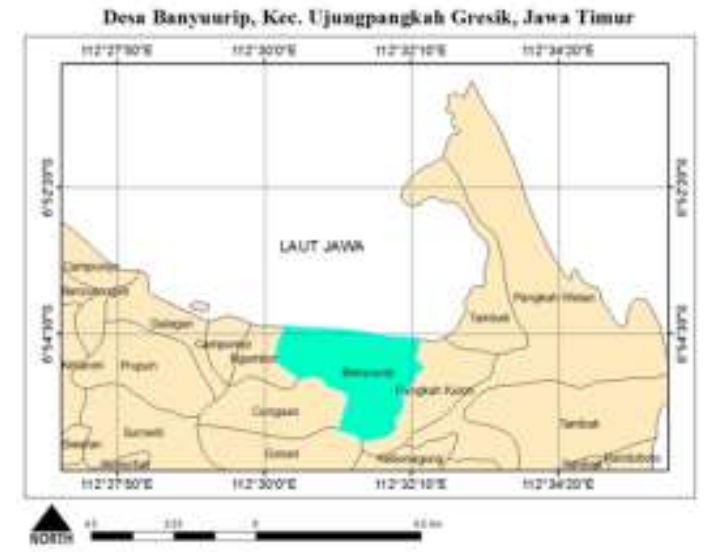

Gambar 1. Peta lokasi Desa Banyuurip, Kecamatan Ujung Pangkah, Gresik

\section{Pembibitan mangrove}

Pembibitan mangrove di Banyuurip Mangrove Center terutama dilakukan untuk jenis Avicennia marina, Avicennia alba, Rhizophora mucronata dan Rhizophora stylosa. Mangrove-mangrove tersebut merupakan mangrove yang banyak terdapat di Desa Banyuurip. Pembibitan dilakukan dengan memanfaatkan buah mangrove yang telah masak dimana untuk A. marina dan A. alba, buah yang dipilih adalah buah yang kulitnya telah terbuka atau yang telah berwarna kekuningan. Untuk $R$. mucronata dan $R$. stylosa, pembibitan dilakukan dengan menggunakan buah yang pada ujung bagian atasnya sudah terbentuk cincin dan tutupnya sudah dapat dilepaskan. Buah $R$. mucronata yang telah matang dan siap untuk digunakan sebagai bibit dicirikan dengan warna hijau tua atau kecoklatan dengan cincin (kotiledon) berwarna kuning (Hiariey and Kaihatu, 2012). Pembibitan tetap dapat dilakukan meskipun tidak memenuhi kriteria di atas, namun pertumbuhannya tidak sebaik jika pembibitan dilakukan dengan buah yang telah masak.

Setelah pemilihan buah yang tepat untuk pembibitan, bibit Avicennia $s p$. direndam di dalam polybag yang berisi air selama beberapa hari sampai kulit buah terkelupas dan tunas akarnya tumbuh. Pada umumnya, bibit akan mengambang jika direndam air. Setelah tunas akar muncul, bibit dapat dipindahkan ke dalam kantung polybag yang telah diisi dengan substrat lumpur. Biasanya dalam rentang waktu 2 minggu, daun akan mulai tumbuh. Berbeda dengan Avicennia sp., proses pembibitan Rhizophora sp. lebih sederhana namun membutuhkan waktu yang lebih lama sampai 
pembibitan dianggap berhasil atau daun mulai tumbuh. Pembibitan dilakukan dengan melepaskan kantung yang melindungi bibit kemudian bibit dapat langsung dipindahkan ke dalam polybag yang telah diisi dengan substrat lumpur. Untuk menjaga agar bibit tetap tegak dan tidak jatuh dilakukan pengikatan dengan bibit lain dalam satu kantung polybag (Gambar 2). Dari proses pembibitan Rhizophora $s p$. ini, daun dapat tumbuh pada rentang waktu 2 sampai 3 bulan.

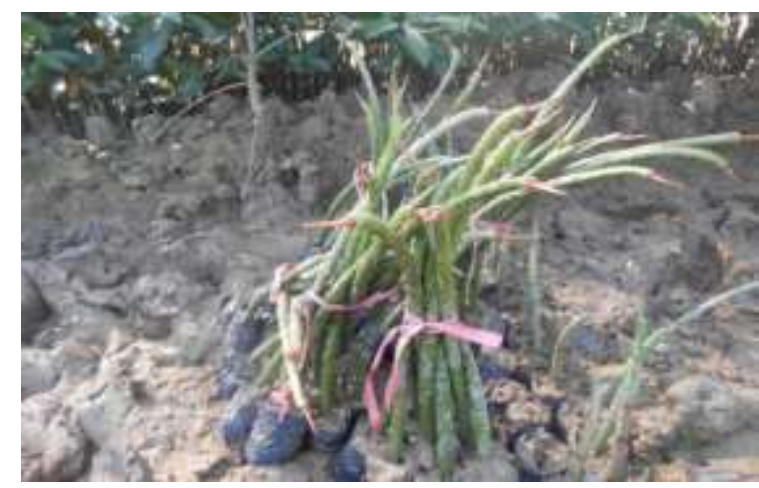

Gambar 2. Bibit Rhizophora sp. yang diikat satu sama lain untuk menjaga agar tetap tegak

Beberapa kesulitan ditemukan dalam proses pembibitan mangrove, diantaranya adalah susahnya menemukan bibit dengan kualitas yang baik. Buah A. marina sering ditemukan sudah dimakan oleh ulat maupun semut merah (Gambar 3). Buah yang tidak baik karena sudah dimakan oleh serangga biasanya cenderung berlubang kecil-kecil (Hiariey and Kaihatu, 2012). Buah seperti ini tentu tidak bisa dijadikan sebagai bibit. Selain gangguan dari ulat atau semut, kepiting juga dapat mengganggu proses pembibitan dengan memakan buah yang sedang dalam proses pembibitan karena buah dari Avicennia $s p$. disukai oleh kepiting. Untuk jenis $R$. mucronata, biasanya kesulitan dalam menemukan buah yang tepat untuk dijadikan bibit karena tidak setiap pohon memiliki buah yang siap untuk dibibitkan. Selain itu, proses pembibitan Rhizophora sp. memakan waktu yang lebih jika dibandingkan dengan Avicennia sp. karena daun pertama baru bisa diamati setelah 2 sampai 3 bulan dari mulai dilakukan pembibitan.

Pembibitan dilakukan dengan dua teknik yaitu teknik dengan polybag dan teknik dengan bedengan (Hiariey and Kaihatu, 2012). Proses pembibitan di Desa Banyuurip menggabungkan teknik polybag dan teknik bedengan. Proses pembibitan diawali dengan teknik polybag yang berukuran 8 x $12 \mathrm{~cm}$. Polybag yang akan digunakan dilubangi terlebih dahulu untuk memudahkan air mengalir dan selanjutnya diisi dengan media tanam. Setiap polybag dapat memuat satu benih mangrove. Media tanam yang digunakan adalah lumpur matang (lumpur yang telah dicampur dengan air) dimana lumpur ini diambil dari lokasi alami habitat mangrove untuk menjaga kesesuaian faktor lingkungan. Lumpur yang sudah dimasukkan ke dalam polybag dipadatkan untuk memudahkan penanaman bibit. Buah mangrove yang telah disiapkan selanjutnya ditancapkan ke dalam polybag dengan kedalaman bervariasi tergantung jenis mangrovenya. Sebagai contoh, $R$. mucronata ditancapkan ke dalam tanah sedalam $5 \mathrm{~cm}$ (Hiariey and Kaihatu, 2012). Setelah bibit siap di polybag lalu dipindahkan ke area persemaian (bedeng) yang cukup terlindungi dari panas matahari.

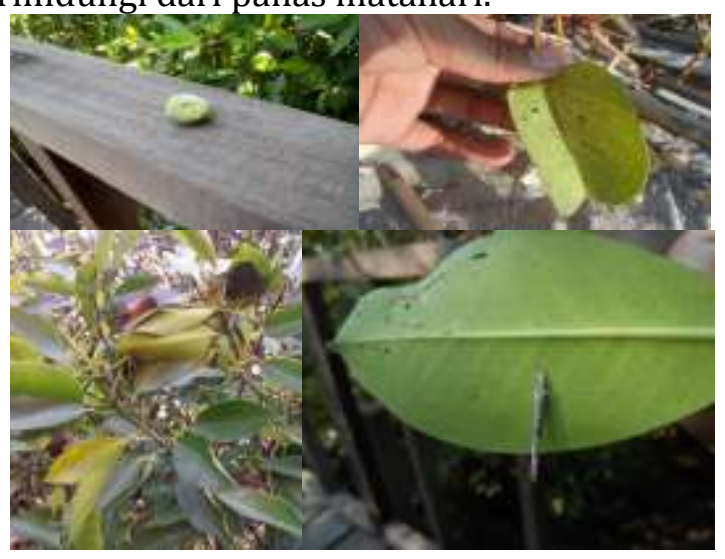

Gambar 3. Kondisi daun maupun buah mangrove yang sudah rusak akibat dimakan ulat, serangga maupun semut.

Area persemaian berada diatas tanah lapang dan datar yang masih terkena pengaruh pasang surut. Namun area persemaian di Desa Banyuurip letaknya cukup jauh dari habitat alami mangrove sehingga sudah tidak mendapat pengaruh pasang surut lagi. Untuk keperluan penyiraman bibit menggunakan pompa yang akan mengalirkan air dari area tambak di sekitar area persemaian. Area persemaian dibuat dengan mencangkul tanah pada kedalaman 5-10 cm untuk memudahkan peletakan polybagpolybag yang telah berisi bibit dan juga untuk memudahkan perendaman bibit. Untuk melindungi area persemaian dari sinar matahari, digunakan jaring peneduh (paranet) dari plastik seperti rafia. Paranet ini mampu menghalangi panas matahari sesuai dengan persentase 
kerapatan materialnya. Selain terlindung dari sinar matahari, area persemaian juga harus bebas dari binatang pemangsa bibit baik binatang dari habitat alami mangrove seperti kepiting atau ketam, maupun binatang dari darat seperti kambing. Area persemaian di Desa Banyuurip karena masih mendapat pengaruh dari habitat alami, masih sering ditemukan kepiting di sekitar area persemaian yang memakan bibit-bibit yang sedang disemaikan. Karena hal ini, pengawasan di area persemaian sangat perlu untuk dilakukan.

\section{Penanaman mangrove}

Setelah tahap pembibitan dilanjutkan dengan proses pemindahan bibit dari polybag ke habitat alaminya. Setiap jenis mangrove memiliki zonasi tumbuhnya dimana Avicennia sp. ditanam di daerah bibir pantai atau di daerah dengan gelombang kuat. Hal ini sesuai dengan karakter dari akar Avicennia sp. yang memiliki akar nafas yang kuat sehingga dapat menahan gelombang yang cukup kuat. Berbeda dengan Rhizophora sp. yang memiliki akar tunjang yang lemah, sehingga lebih cocok ditanam di daerah yang terlindung dari gelombang. $R$. stylosa memiliki akar yang lebih kuat dibandingkan dengan $R$. mucronata, namun lebih lemah dibandingkan dengan akar dari A. marina. Penanaman mangrove di habitat alaminya dapat dilakukan dengan menambahkan bantuan kayu yang ditancapkan ke dalam tanah sebagai penopang untuk menjaga agar bibit baru tersebut tidak roboh.

Saat ini, Kelompok Pelestari Mangrove Banyuurip memiliki pusat pembibitan mangrove pada lahan seluan $336 \mathrm{~m}^{2}$ dengan kapasitas produksi sekitar 47.500 bibit mangrove (Gambar 4). Bibit-bibit ini sebagian dijual dan sebagian lagi digunakan sendiri untuk ditanam di kawasan Banyuurip. Bibit yang dijual biasanya adalah bibit yang telah berumur 100 hari dan diletakkan dalam polybag dalam kondisi padat untuk memperkuat ketahanannya selama proses pengiriman.

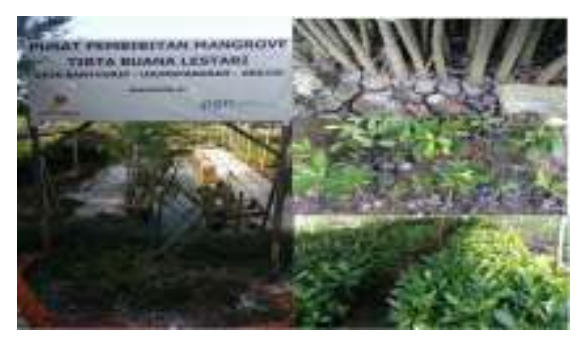

Gambar 4. Pusat pembibitan mangrove Tirta Buana Lestari Desa Banyuurip

\section{UCAPAN TERIMAKASIH}

Kegiatan ini terlaksana karena dibiayai oleh Program Doktor Mengabdi Universitas Brawijaya tahun 2017. Terimakasih kami ucapkan kepada Kepala Desa Banyuurip dan Bapak Abdul Mughni selaku pelaku pembibitan mangrove di Desa Banyuurip atas ijin dan bantuannya sehingga kegiatan ini dapat terlaksana dengan baik.

\section{DAFTAR PUSTAKA}

Bengen, D.., 1999. Pedoman Teknis Pengenalan Dan Pengelolaan Ekosistem Hutan Mangrove. Pusat Kajian Sumberdaya Pesisir dan Lautan, Institut Pertanian Bogor, Bogor.

Gunarto, 2004. Konservasi Mangrove Sebagai Pendukung Sumber Hayati Perikanan Pantai. J. Litbang Pertan. 23, 15-21.

Hiariey, L.S., Kaihatu, M.M., 2012. Teknik pembibitan mangrove (Rhizophora mucronata dan Sonneratia alba) di Perairan Desa Passo Kecamatan Teluk Ambon Dalam (Laporan Penelitian Mula Bidang Ilmu). UPBJJ UT, Ambon.

Nagelkerken, I., Blaber, S.J.M., Bouillon, S., Green, P., Haywood, M., Kirton, L.G., Meynecke, J.-O., Pawlik, J., Penrose, H.M., Sasekumar, A., Somefield, P.J., 2008. The habitat function of mangroves for terrestrial and marine fauna: A review. Aquat. Bot. 89, 155-185.

Noor, Y.R., Khazali, M., Suryadiputra, I.N.N., 2002. Panduan pengenalan mangrove di Indonesia, 2nd ed. PHKA/WI-IP, Bogor.

Pontoh, 0., 2011. Peranan Nelayan Terhadap Rehabilitasi Ekosistem Hutan Bakau (Mangrove). J. Perikan. Dan Kelaut. Trop. 7, 73-79.

Spalding, M., Kainuma, M., Collins, L., 2010. World Mangrove Atlas. Earthscan.

Suryawan, F., 2007. Keanekaragaman Vegetasi Mangrove Pasca Tsunami Di Kawasan Pesisir Pantai Timur Nangroe Aceh Darussalam. Biodiversitas 8, 262-265. 